\title{
INTERNACIONALIZAÇÃO COMO PRÁTICA LOCAL: UM OLHAR SITUADO SOBRE O PAPEL DA LÍNGUA NO ENGLISH CLUB E NO \\ CURSO DE MEDICINA
}

\author{
INTERNATIONALIZATION AS A LOCAL PRACTICE: A SITUATED VIEW ON \\ THE ENGLISH CLUB AND IN THE MEDICINE COURSE
}

\author{
Ruberval Franco Maciel $^{1}$, Vitor Souza Vergara ${ }^{2}$
}

\begin{abstract}
RESUMO: A internacionalização representa um conceito que tem recebido cada vez mais destaque nas políticas e agendas do ensino superior. Esse termo requer aprofundamentos e teorizações, sobretudo, problematizações que vão além do aspecto mobilidade acadêmica ao se conceber significados mais amplos sobre esta questão, com destaque ao aspecto local. Neste artigo será explorado o aspecto de internacionalização como prática local ou internacionalização em casa, apontando para estratégias de implementação de ações voltadas para o papel da língua na internacionalização do ensino superior. Para tanto, será discutido o English club como um espaço para atividades de desenvolvimento linguístico planejado e executado como uma atividade de extensão por acadêmicos do curso de medicina de uma universidade pública. As discussões tomarão como base os estudos de Knight (2008), Rocha e Maciel (2015; 2018), Martinez (2017), Menezes de Souza (2018), Vergara e Maciel (2018a.b.), Baumvol e Sarmento (2016), entre outros.
\end{abstract}

PALAVRAS-CHAVE: internacionalização; internacionalização como prática local; internacionalização em casa.

ABSTRACT: Internationalization represents a concept that has received increasing attention in the policies and agendas of higher education. This term requires more discussion and theorizing, regarding, problematizations that go beyond the aspect of academic mobility in devising broader meanings on this matter, with emphasis on the local aspect. This article will explore the internationalization aspect as local practice or internationalization at home, pointing to strategies for implementing actions focused on the role of language in the internationalization of higher education. To this end, the English club will be discussed as a space for linguistic development activities planned and implemented as an extension activity by academics of the medicine program of a public university. Discussions will rely on the studies of Knight (2008), Rocha and Maciel (2015, 2018), Martinez (2017), Menezes de Souza (2018), Vergara and Maciel (2018a.b.), Baumvol e Sarmento (2016), among others.

\footnotetext{
${ }^{1}$ Pós-Doutor pelo programa de PhD in Urban Education da City University of New York - Estados Unidos. Doutor em Estudos Linguísticos e Literários de Inglês pela USP.

${ }^{2}$ Graduação em Medicina pela UEMS.
} 
KEYWORDS: internationalization; internationalization as local practice; intenationalization at home.

\section{Introdução}

A internacionalização é tema que tem ganhado interesse e tem sido amplamente debatido no cenário educacional. Na Europa, por exemplo, há muito tempo o ensino superior tem sido marcado por fluxos de estudantes e docentes. Essa política recebeu mais força a partir da Declaração de Bolonha em 1999 ao se propor uma modernização das Instituições de Ensino Superior, para enfrentar os desafios da globalização e garantir competitividade no mercado de trabalho.

Para se compreender a importância da Declaração de Bolonha, é necessário se entender outros contextos e, para os autores Bianchetti e Magalhães (2015), por se tratar de um processo complexo, é importante entender, ainda, todo o contexto histórico e geográfico da União Europeia (UE). Desde a antiguidade, a Europa tem sido o centro do conhecimento, sendo pioneiros no seu processo civilizatório e implantando a chamada "visão eurocêntrica". No entanto, principalmente nas últimas décadas, a Europa vem perdendo seu protagonismo, especialmente frente ao crescimento dos Estados Unidos (EUA) no período pós-guerra mundial. Buscando uma federação, com a superação dos problemas e diversidade étnica e cultural, foi criada a União Europeia em 1992, baseada na antiga Comunidade Econômica Europeia. Paralelamente a esses acontecimentos, a Declaração de Bolonha de 1999 reflete as medidas tomadas no campo educacional para se reafirmar o protagonismo europeu. Trata-se de uma declaração conjunta dos ministros de educação europeus visando elevar sua competitividade e atração mundial, criando uma Área Europeia de Ensino Superior (AEES) para haver compatibilidade nos sistemas de ensino, mobilidade de professores e alunos e empregabilidade de egressos.

A partir desse tratado, começou-se a pensar aspectos como certificação internacional, proficiência linguística, transculturalidade, bem como revalidações de créditos obtidos em outras universidades estrangeiras. Apesar do tratado ter tido uma ação na UE, suas implicações a respeito da internacionalização não se restringem à Europa, mas se espalham 
para as outras partes do mundo, devido à importância do tema de internacionalização no cenário mundial.

Em outros contextos, como é o caso do Brasil, as políticas de internacionalização, durante muito tempo, concentravam-se em ações de incentivos por parte de agências financiadoras como CAPES e CNPq para a formação de recursos humanos em um movimento exógeno em direção aos lugares tidos como centros de referências situados na Europa e nos Estados Unidos. Esse cenário de política de internacionalização para formação de recursos humanos tem diminuído, uma vez que as universidades brasileiras já possuem seus centros de formação em programas de mestrado e doutorado. Vale ressaltar que pensar em internacionalização considerando apenas o movimento de diáspora em busca de conhecimento de referência no exterior, representa uma visão colonizada (MARTINEZ, 2017) do que pode ser concebido como internacionalização. Atualmente, há ainda programas de incentivos a professores visitantes, estágio doutoral sanduíche e programas de cátedras, entre outros, com número reduzido de bolsas comparados a anos anteriores, sobretudo no período do programa Ciências Sem Fronteiras (MENEZES DE SOUZA, 2018).

Neste sentido, a internacionalização, conforme Knight (2008), é um termo que vem cada vez mais sendo utilizado para discutir a dimensão internacional do ensino superior. Esse assunto tem se tornado um dos maiores aspectos influenciadores no que ser refere ao contexto educacional, principalmente no século XXI em que a nova realidade de globalização do mundo impacta diretamente na internacionalização. Através desse raciocínio, a internacionalização torna-se um processo que integra as dimensões internacionais, transculturais e locais nos contextos de ensino, pesquisa e extensão no ensino superior.

A internacionalização, conforme Rumbley e Altbach (2016), pode assumir diferentes entendimentos dependendo do contexto em que está inserida. Para esses autores, dois aspectos principais ou duas vertentes desse entendimento podem ser destacados: uma global e uma local.

No que se refere ao aspecto global, quatro fatores em que esse entendimento está muito ligado podem ser elencados, sendo eles:

I. A política de mercado (influenciada pelo neoliberalismo);

II. As estratégias adotadas pelos governos e universidades para adequar o ensino superior nos âmbitos institucionais e nacionais, 
III. As questões de negócio envolvendo mobilidade de estudantes, cursos de línguas, dentre outras ações e programas.

IV. Os impactos dos desenvolvimentos de novos serviços e de tecnologias da informação afetou diretamente no processo de internacionalização ao possibilitar mais acessibilidade aos fluxos internacionais de conhecimento. Em função disso, houve um aumento no número de parcerias entre as instituições educacionais.

Os quatro fatores acima podem ser identificados principalmente no contexto de universidades que dependem do capital financeiro privado. Nesses contextos, a parte educacional se torna uma commodity e não necessariamente um bem público. Há a preocupação de atração de alunos e a preocupação com a visibilidade na universidade no cenário internacional. Há, ainda, a preocupação com a mobilidade virtual e internacionalização virtual, contemplados por cursos online e projetos colaborativos virtuais.

Em uma visão mais local, o entendimento está mais focado nos aspectos práticos da internacionalização. Isso pode ser identificado, por exemplo, em ações institucionais, tais como na criação de programas de mobilidade e na adequação do campus a uma realidade internacional. Os aspectos podem incluir a ampliação de possibilidades de experiências estudantis, incorporando novas descobertas em ações de pesquisa, em trabalhos e atividades voluntárias de internacionalização como prática local. Todos esses aspectos necessitam de elaboração de editais específicos em consonância com as políticas vigentes de agências de fomentos.

\section{A expansão dos conceitos de internacionalização no ensino superior internacional}

A palavra internacionalização pode ser entendida de diferentes maneiras dependendo do seu contexto sócio histórico. Ao discutir a origem e seus significados, Knight (2003) chama atenção para o fato de que a internacionalização é um termo que já existe há muito tempo e que, há séculos, é amplamente abordado na ciência política e nas relações governamentais. No entanto, esse conceito começou a ser empregado na área educacional a partir dos anos 1980. Antes, a partir da década de 1960, segundo Knight (2008), os termos mais utilizados eram cooperação internacional, relações internacionais e educação internacional e se referiam principalmente a desenvolvimento de projetos, estudantes 
estrangeiros e acordos acadêmicos internacionais e culturais, conforme destacado na sistematização a seguir.

\begin{tabular}{l} 
Tradicionalmente - Tem sido usado por anos em ciência política e relações \\
governamentais. \\
\hline
\end{tabular}

- Os termos “educação internacional "e a "cooperação internacional " eram mais utilizados;

Durante anos 1960 - Referência a atividades como desenvolvimento de projetos, estudantes estrangeiros e acordos acadêmicos e culturais internacionais

- Cenário educacional;

Década de 1980 - Atividades como estudo no exterior, estudos de idiomas, acordos institucionais e àreas de estudos.

\begin{tabular}{ll}
\hline & - Processo de integração de uma dimensão internacional e \\
& intercultural nas funções de ensino, pesquisa e serviço da instituição; \\
& - Qualquer esforço sistemático destinado a tornar o ensino superior \\
Década de 1990 & sensível aos requisitos e desafios relacionados com a globalização \\
& das sociedades, economia e mercados de trabalho.
\end{tabular}

- Ênfase na mobilidade acadêmica que inclui estudantes, pesquisa, programas e provedores que se deslocam através das fronteiras;
Século XXI - Atividades comerciais e de mercado;
- Crescimento em redes acadêmicas e parcerias baseadas em benefícios mútuos e colaboração.

Figura 1: Internacionalização ao longo dos anos, resumida a partir de Knight (2008). 
Dentre os muitos termos existentes, Knight (2008) elenca, ainda, várias outras denominações - educação multicultural, educação intercultural, educação à distância e educação global. Conforme ilustrado no quadro, nos anos 1980 a internacionalização começou a ser mais difundida e utilizada e desde essa época seu conceito foi sofrendo modificações com o tempo. Inicialmente seu enfoque estava relacionado a estudos no exterior, estudo de línguas, acordos institucionais e áreas de estudo. Posteriormente, na década de 1990, muitos enfoques foram dados. Primeiramente passou a abordar múltiplas atividades, programas e serviços que se baseiam em estudos internacionais, intercâmbios internacionais e cooperação técnica. Outra ênfase usada foi o processo de integração de dimensão internacional e intercultural no ensino, pesquisa e serviços de uma instituição. Porém, essa definição recebeu críticas por estar baseada na instituição e, devido a isso, um conceito mais amplo surgiu definindo internacionalização como qualquer esforço em fazer o ensino superior responsável pelas necessidades e desafios relacionadas a globalização da sociedade, economia e mercado de trabalho. Novamente, esse conceito recebeu críticas, por somente situar a dimensão internacional no contexto externo, de modo que no início do século XXI outro enfoque foi adotado, para especificar o uso do termo internacionalização, assumindo a característica de definição do trabalho. Por essa definição, compreende-se internacionalização nos níveis nacionais, setoriais e institucionais como um processo de integração das dimensões internacional, intercultural e global com os propósitos e funções do ensino superior nos níveis nacionais e institucionais.

Para alguns autores, as características da educação estão ligadas ao processo de globalização e às determinações de organismos internacionais multilaterais. Segundo Morosini (2006), a internacionalização precisa ser vista como um processo complexo que passou por algumas fases: a fase de dimensão internacional, presente no século XX; a fase de educação internacional, presente entre a segunda guerra mundial e término da guerra fria, onde o interesse nas atividades estava voltado para razões políticas e segurança nacional; e a terceira e última fase, a internacionalização do ensino superior, de início no pós guerra fria, intimamente ligada à globalização e à regionalização das sociedades, impactando diretamente no ensino superior.

Além da internacionalização, outros termos merecem destaque. Dentre eles estão a educação sem fronteiras (borderless education) e a educação transfronteiriça (cross-border 
education) que segundo Knight (2003), visa dar menos importância às fronteiras geográficas, bem como disciplinares que usualmente limitavam a internacionalização do ensino superior tradicionalmente. Há uma diferença entre os termos, uma vez que educação sem fronteiras trata a questão das fronteiras como de pouca importância ou que não acarreta tantas consequências no ensino. Por outro lado, educação transfronteiriça deixa fronteiras em destaque, no sentido de focar nos aspectos legais como nos financiamentos, qualidade do ensino e validação de cursos ou diplomas realizados no exterior. Ainda, termos como educação transnacional, educação virtual e globalização ganham destaque e passam a ser empregados nas discussões sobre internacionalização.

No contexto educacional atual, novas realidades têm surgindo e trazem consigo muitos desafios. Nesse cenário, Knight (2008) elenca oito desafios principais.

$\mathrm{O}$ primeiro refer-se à globalização. Trata-se de um termo muito abrangente e possui impactos diretos em muitos setores da sociedade como por exemplo, no fluxo de pessoas, ideias, culturas, valores, conhecimento e economia. Isso resulta em relações mais ampliadas e torna o mundo mais conectado e interdependente. Por consequência, impacta na internacionalização em seus vários aspectos, tais como no currículo e no ensino, na mobilidade acadêmica, nos programas internacionais, no desenvolvimento de projetos internacionais, nos estudos de línguas estrangeiras, nas transações comercias, dentre outros aspectos.

Outro desafio refere-se à regionalização como um resultado da globalização. Isso possibilita o surgimento de blocos não somente econômicos como é o caso das universidades da União Europeia. Assim, consórcios e alianças são formados para facilitar os fluxos e serviços no contexto da educação internacional do ensino superior.

O terceiro desafio está relacionado às tecnologias de informação e comunicação, o que possibilita aos acadêmicos a ter maior acesso a informações e contatos internacionais. Além disso, as novas tecnologias possibilitam oportunidades de realização de cursos a distância, desenvolvimento de programas educacionais, levando o estudante a ter um currículo internacional e novos processos de aprendizado.

O quarto desafio refere-se ao surgimento de novo provedores, com desenvolvimento de novos métodos no ensino e novos programas. Dentre os novos provedores encontram-se as companhias de mídia, multinacionais, universidades corporativas e associações e 
organizações de redes profissionais. Geralmente, são voltadas para o treinamento e ensino, não possuindo um foco evidente em pesquisa.

Outro desafio relatado são as fontes de financiamento. Para isso, um dos caminhos seguido é a diversificação, a privatização e a comercialização do ensino superior e pesquisas. As principais fontes são o próprio governo através das receitas e impostos arrecadados, patrocínio e comercialização das pesquisas e dos conhecimento científicos.

Questões que abrangem o global são um sexto desafio a ser considerado, delas podemos citar as mudanças no meio ambiente, crescimento populacional, segurança, aquecimento global, imigração, terrorismo, direitos humanos. Eles exigem colaboração internacional, através de agência governamentais multilaterais e organizações não-governamentais, bem como do ensino superior.

O sétimo desafio incluído é o constante aprendizado. Cada vez mais conhecimento é gerado, e atualizações são feitas constantemente, o que era verdade em uma época pode não ser em outra. Nesse contexto, o importante é manter-se num aprendizado contínuo, sempre atualizando suas habilidades para contribuir no nacional, internacional e local.

Por fim, é apresentado o crescimento de atores envolvidos na promoção, fornecimento e regulação da dimensão internacional do ensino superior. Dependendo da sua atuação podem desempenhar diferentes papeis, abrangendo níveis internacionais, ou atuando mais nacionalmente e regionalmente. Dentre eles podemos citar, departamentos governamentais e agências governamentais, organizações não-governamentais, associações profissionais, fundações, instituições educacionais e fornecedores.

\section{Internacionalização como prática local}

Muitas análises foram feitas sobre a internacionalização ao longo do tempo, muitos entendimentos foram abordados, alguns se mantiveram, outros foram deixados de lado e novos emergiram. Uma das características mais marcantes da internacionalização, refere-se a internacionalização em casa ou como prática local. Essa perspectiva não está restrita à lógica de mobilidade externa, mas busca pensar na internacionalização dentro do próprio campus da universidade.

Internacionalização como prática local ou internacionalização em casa é um dos novos termos surgidos para designar os aspectos práticos da internacionalização dentro da 
universidade ou instituição. De acordo com Beelen (2016), há seis desafios-chave no que concerne à internacionalização em casa: estratégias e prioridades; atividades implantadas pelas universidades para implementar suas estratégias, produção internacional e suas avaliações, experiência e habilidade do corpo discente, desenvolvimento profissional voltado para a internacionalização como prática local e o papel dos profissionais estrangeiros no processo de internacionalização em casa.

Assim, pensar no internacional dentro do local é um dos primeiros passos que uma universidade deve dar para a sua internacionalização. Para Gaalen e Gielesen (2016) a internacionalização como prática local se refere a toda atividade dentro do currículo realizada dentro da própria instituição ou curtas viagens com fins acadêmicos, realizadas no exterior, acompanhadas por profissionais da instituição de origem. De maneira mais detalhada, Knight (2008) menciona que a internacionalização como prática local se refere aos aspectos da internacionalização que acontecem no próprio campus. Nesse contexto são incluídas as dimensões internacionais e transculturais no processo de ensino e aprendizado, pesquisas, atividades extracurriculares, relações com a cultura e comunidades étnicas locais, bem como a integração de acadêmicos estrangeiros na vivencia e atividades da instituição.

Ainda sob o enfoque da internacionalização como prática local, algumas particularidades do mundo atual merecem ser destacadas. Sob esse aspecto, Robson (2017) aponta que, o processo de globalização e desenvolvimento de novas tecnologias podem ajudar no processo de internacionalização em casa ao conectar regiões de forma virtual. Por intermédio dessas conexões, a barreira física pode ser superada, sendo, portanto, ofertadas aos alunos e aos funcionários oportunidades e experiências de aspectos internacionais no meio local. Nesse sentido, pesquisas e trabalhos das comunidades externas podem ser acessados na própria comunidade local. Um exemplo disso se refere a projetos de telecolaboração internacional de ensino e pesquisa de formação de professores transnacionais. Nesse desenho, Morgan, Martin e Maciel (2017) relatam uma experiência em que acadêmicos em formação inicial de uma universidade canadense e de uma brasileira interagiram de forma visual para discutir assuntos em comum no que se refere à formação de professores de inglês em um contexto global.

Outra característica que merece ser abordada sobre a internacionalização em casa diz respeito às línguas adicionais, principalmente a língua inglesa. Sobre esse aspecto, Baumvol e Sarmento (2016) apontam que as línguas adicionais podem funcionar como uma possibilidade 
para que alunos e professores possam ter acesso a práticas internacionais, sendo que a linguagem permitiria que os indivíduos se conectassem entre si, com as diferentes comunidades e culturas e atuassem no mundo.

Dentro da discussão da internacionalização como prática local ou em casa, um aspecto que ganha centralidade é a transculturalidade. Nesse sentido, Rocha e Maciel $(2016 ; 2018)$ chamam atenção para que internacionalização como prática local deva ser vista como um olhar mais atento para como esse processo pode influenciar na des/reconstrução das identidades, subjetividades e territorialidades. O referidos autores sugerem que tenhamos um olhar sensível para percebermos como os aspectos de transculturalidade acontecem e quais transformações se fazem presentes nos contatos com a alteridade. A partir disso, há um olhar situado para a interrelação entre culturas como resultado dos fluxos da globalização cultural. Ainda, para os referidos autores, a transculturalidade pode-se traduzir nas mais variadas formas. Uma delas está relacionada à diversidade de línguas e linguagens, tomando diferentes formas em meio ao movimento, ao cruzamento e à transgressão de fronteiras levando a um contexto de transformação, no qual, se vivencia um processo de intensa e dinâmica interpenetração de ideias, valores, discursos e práticas. Nessa ótica, a transculturalidade serviria, dentro da prática local, como uma maneira de validação da pluralidade cultural, dentro e fora da sala de aula, no currículo e nos afazeres pedagógicos, contribuindo para as diferentes formas de se conceber e se construir conhecimento, em meio ao dinâmico contexto de trocas culturais, produzidos pelos fluxos e redes de colaboração cultural (ROCHA e MACIEL, 2018).

Visando contemplar essas questões, segundo Knight (2008), algumas estratégias acadêmicas podem ser adotadas pelas universidades e outras instituições, podendo ser agrupadas em quatro grandes áreas.

$\mathrm{Na}$ primeira, o destaque se dá aos programas acadêmicos. Nesse grupo, estão as estratégias de estudo de línguas estrangeiras, programas de intercâmbio estudantil, estudantes internacionais, visitas técnicas, dupla diplomação, estudos e trabalhos no exterior, dentre outros programas. Na segunda área, estão a pesquisa e a colaboração acadêmica. No que se refere às estratégias, a autora aponta a adoção de áreas e temas centrais na pesquisa, realização de pesquisas em conjunto, na realização de conferências e de seminários, publicações de artigos, programas de intercâmbio de pesquisa, parcerias em pesquisa e acordos de pesquisa. 
As relações externas é quarta área citada, que pode ser dividida em doméstica e transfronteiriça. Na parte doméstica, são contempladas as parcerias com organizações não-governamentais ou do setor público/privado, serviços comunitários e projetos transculturais de trabalho e programas de treino e ensino para parceiros e clientes internacionais. Na parte transfronteiriça, temos as estratégias de desenvolvimento de projetos internacionais assistenciais, comercialização de programas educacionais, aberturas de filiais, realização de acordos e parcerias, programas externos para ex-alunos e desenvolvimento de programas de pesquisa e serviços.

Por último, a autora destaca a área extracurricular, da qual as seguintes estratégias podem ser destacadas: associações e agremiações estudantis, realização de eventos internacionais e transculturais no campus, criação de vínculos com os diversos grupos étnicos e culturais e criação de grupos de apoio e suporte. A seguir discutiremos dois contextos de internacionalização como prática local mediados pela língua inglesa no curso de medicina.

\section{Internacionalização como prática local no curso de medicina da UEMS}

No que se refere ao aspecto de internacionalização como prática local e o papel da língua nesse contexto, ilustramos, a seguir, dois cenários no curso de medicina. No primeiro, discutiremos o papel da língua inglesa na disciplina de Introdução aos fundamentos científicos (IFC) no segundo ano do curso de medicina. Na sequência, abordaremos como uma disciplina da graduação pode despertar em um grupo de acadêmicos do curso de Medicina o interesse para elaboração e promoção de um projeto de extensão voltado para o letramento acadêmico em língua Inglesa.

\section{Internacionalização como práticas local: aspectos curriculares}

Conforme já abordado nesse artigo, dentre as várias estratégias de internacionalização, a internacionalização em casa é um dos elementos importantes que perpassa o currículo (KNIGHT, 2008) e umas das possibilidades de implementação pode começar pelo papel das línguas adicionais (BAUMVOL e SARMENTO, 2016) na universidade. Nesse sentido, o curso de medicina da UEMS, de forma transversal, contempla 
a língua inglesa no segundo ano na disciplina de Iniciação aos Fundamentos Científicos (IFC). A proposta se pautou em uma perspectiva de metodologia ativa (VERGARA e MACIEL, 2018 a,b), seguindo a orientação do Problem Based Learning (PBL) e de um processo de design e redesign (COPE e KALANTZIS, 2008; MACIEL e BARBOSA, 2018). Nas aulas, foram abordados artigos científicos da área médica cujas temáticas foram relacionadas aos assuntos estudados nas tutorias dos demais módulos. A ênfase, no início, se deu no desenvolvimento de gêneros de apresentação oral. Nas tutorias das aulas de língua inglesa, a turma foi dividida em 4 grupos de 12 alunos em horários distintos. Em forma de sala de aula invertida, os textos eram lidos previamente e mapas conceituais eram elaborados como preparação prévia para discussão nas aulas.

Para ilustração desse aspecto, pautaremo-nos no conceito de design e redesign. Para Maciel e Barbosa (2018), os textos, a partir de uma perspectiva multimodal, são compostos por diferentes designs e personificam-se socialmente por diversas formas de expressão da linguagem, além da linguística. A esse posicionamento, os referidos autores destacam a importância de relacionar, organizar e selecionar os elementos das linguagens dos textos multimodais para que os alunos desenvolvam capacidades de associação, renegociação de possibilidades de construção dos sentidos. Dessa forma, em consonância com uma perspectiva de metodologia ativa, as aulas buscavam estabelecer relações com temáticas abordadas em outros módulos temáticos, por exemplo, saúde da mulher. A partir dai, os textos eram sugeridos pelos alunos ou pelos professores tutores.

Nas quatro imagens a seguir, ilustramos com o conhecimento foi sendo co-construído pelos alunos por intermédio de diferentes modalidades e sendo apropriado pelos alunos, de forma sistemática mediado pela lingua inglesa. Os aspectos linguísticos eram trabalhados de acordo com o gênero abordado em cada aula desde a sistematização do artigo científico até a apresentação oral em video como o produto final. A imagem A ilustra como o texto era apresentado aos alunos. A imagem B ilustra como o aluno sistematiza e interage com o mapa conceitual e recebe instruções e feedback para o desenvolvimento do gênero apresentação oral de trabalho cientifico. A image $\mathrm{C}$ ilustra um workshop para preparação em video, em que várias modalidades são exploradas, como por exemplo, a escolha do enquadramento do vídeo, a utilização da linguagem corporal, o cuidado com a empostação de voz, a utilização de aspectos visuais com inclusão de mapas conceituais abordados na aula anterior, bem como com critérios para a edição final. Essa etapa contou com a participação de 
uma jornalista da universidade. Relatos dos alunos no final do módulo demostraram que a perspectiva de metodologia ativa dentro da disciplina de introdução aos fundamentos científicos se diferenciava bastante das experiências de aprender inglês durante a vida escolar dos acadêmicos. Além disso, as aspectos de multimodalidade contribuíram para terem mais autoconfiança e no aprimoramento do gênero apresentação oral de trabalho acadêmico (para mais detalhes, ver Hodgson, $2019^{3}$ ).

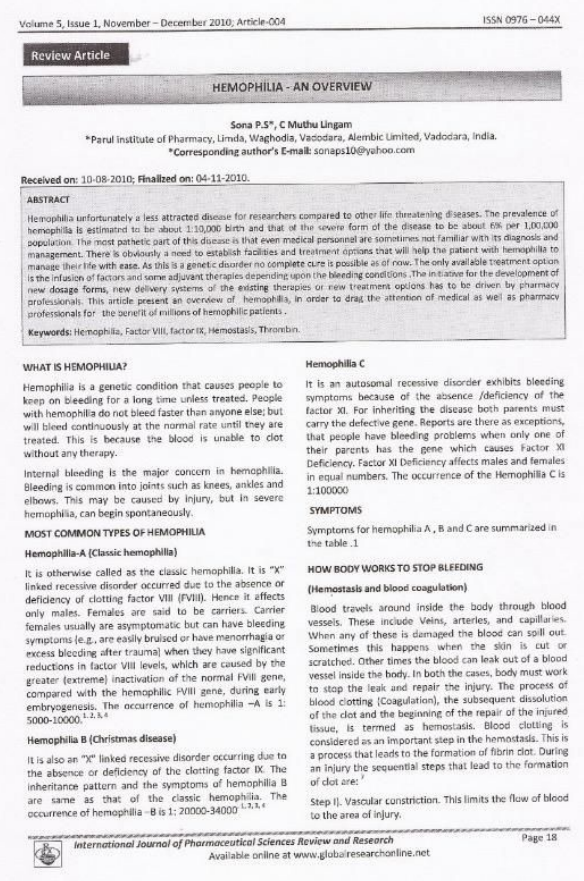

Figura A: artigo que possibilitou a montagem do mapa mental e a realização da apresentação.

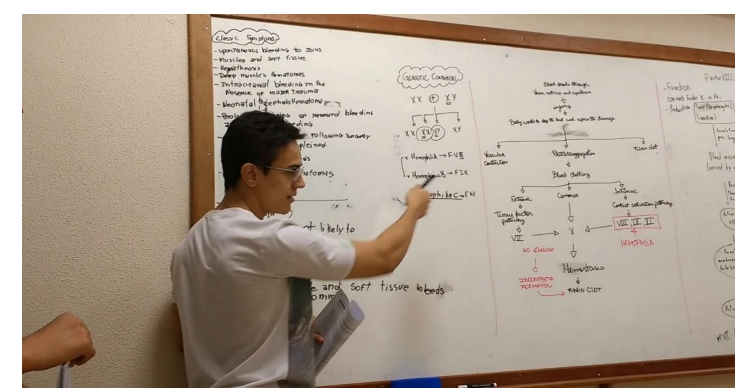

Figura B: Acadêmico do $3^{\circ}$ ano apresentando o artigo 'Hemophilia - an overview'

\footnotetext{
${ }^{3}$ HODGSON, L. M. Coconstruções rizomáticas do conhecimento de inglês acadêmico em um curso de medicina. Dissertação de Mestrado em Letras. Universidade Estadual de Mato Grosso do Sul. Campo Grande, MS, 2019.
} 


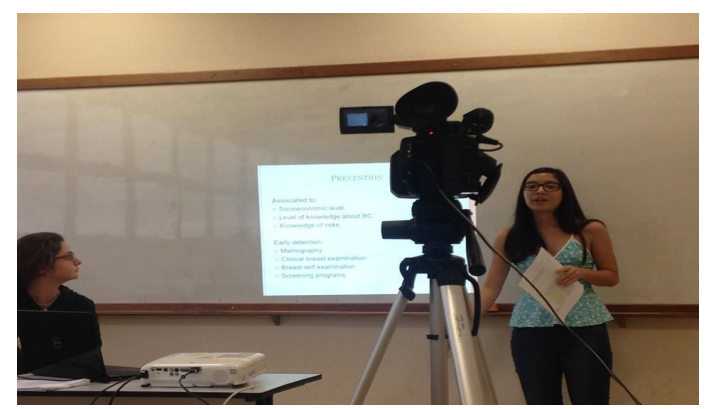

Figura C: workshop audio visual - apresentação multimodal

\section{Internacionalização como práticas local: aspectos Extra curriculares}

A experiência dos alunos do curso de medicina com a inserção das aulas de língua inglesa como parte integrante do currículo de forma transversal, conforme mencionado anteriormente, serviu de inspiração para o surgimento de um projeto de extensão, o English Club. O English Club se pautou em metodologias semelhantes àquelas vivenciadas durante as aulas. $A$ proposta surgiu quando cinco acadêmicos do curso de medicina tiveram a iniciativa de desenvolver, planejar e executar o projeto English Club. A ação buscou incluir aspectos da internacionalização dentro do curso de medicina da UEMS, ao explorar literatura estrangeira médica e oportunizar aos acadêmicos a discutir as publicações publicadas internacionalmente.

O English club foi registrado como um subprojeto de um projeto institucional "Internacionalização do ensino superior como prática local: transculturalidade, proficiência linguística, mobilidade, projeção institucional e integração acadêmica. A proposta visava ampliar a participarão de alunos para além do curso de Letras, onde os aspectos linguisticos já são desenvolvidos pelo programa Idiomas sem

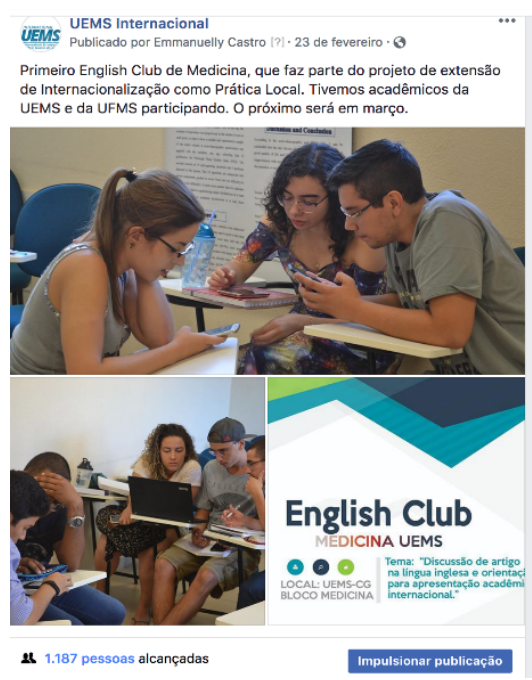
Fronteiras. 


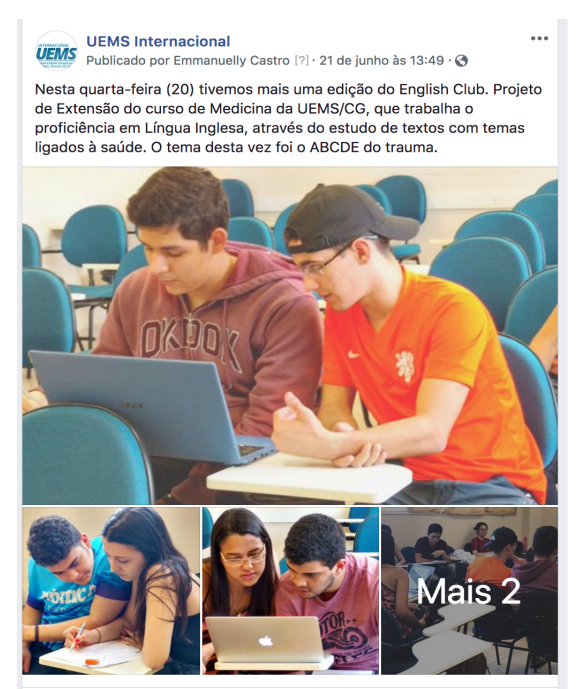

Figura D: Interação dos participantes no proejo English Club.

Pautamos-nos em dois participantes que buscaram avaliar tal experiência. Primeiro, Hodgson (2019, p.140), em sua dissertação de mestrado que investigou a inserção da língua inglesa no curso de medicina em questão afirma que as aulas de inglês da graduação podem ser considerada como uma possibilidade de affordance ${ }^{4}$. Para a autora, "ao se ter acesso a esse mundo linguístico, o aprendiz desenvolve a percepção das affordances, disponibilizadas nesse universo linguístico que ele quer ou precisa se engajar". Outro aspecto, é destacado por um dos bolsitas ministrantes do projeto de extensão. Para Otta (2018), o estímulo acadêmico à cooperação e à participação científica ativa em língua estrangeira, já logo no início de sua formação acadêmica, favorece o desenvolvimento de uma cultura local de internacionalização do saber acadêmico, capaz de possibilitar maior acesso à informação e mais expressividade internacional ao conhecimento local.

\section{Considerações Finais}

A internacionalização é uma temática que vem sendo discutida há algum tempo, adquirindo novos significados e entendimentos com o passar dos anos, mas que principalmente durante esse século tem elevado sua importância no currículo das Instituições de Ensino Superior. Nesse contexto, o principal meio de colocar a internacionalização no contexto educacional é através da internacionalização como prática local e estratégias

\footnotetext{
${ }^{4}$ Para Paiva (2011), affordance se refere às noções de relações, possibilidade, oportunidade, imediatismo e interação.
} 
acadêmicas, como o papel da língua no currículo universitário e inserção de English Club se traduzem em ações utilizadas no ensino superior.

A partir dos dois contextos ilustrados nesse artigo, o de línguas adicionais pode representar uma possibilidade de professores buscar outras perspectivas metodológicas e outras experiências de aprendizagem além das possiblidades mais tradicionais no ensino de línguas. Conforme apresentado nesse artigo, a língua inglesa introduzida de maneira transversal dentro de uma disciplina que visa apresentar o gênero acadêmico pode ser expandida a partir de uma perspectiva multimodal. Além disso, a experiência pode contribuir para fomentar a agência nos alunos na implementação de cursos de extensão para as áreas afins a partir da perspectiva adotada no curso de graduação contemplando, assim, dois aspectos de internacionalização em casa.

\section{REFERÊNCIAS}

BAUMVO, L. K., \& SARMENTO, S. (2016). A internacionalização em casa e o inglês como meio de instrução. In M. S.Beck, M. Moritz, M. Martins, \& V. Heberle (Eds.), ECHOES: Further Reflections on Language and Literature (pp. 65-82). Florianópolis: EdUFSC.

BEELEN, J. Global at Home: Internationalisation at Home in the 4th Global Survey. Global and Local Internationalization, 149-154. Sense Publishers, 2016.

BIANCHETTI, L.; MAGALHÃES, A. M. Declaração de Bolonha e internacionalização da educação superior: protagonismo dos reitores e autonomia universitária em questão. Avaliação (Campinas), Sorocaba, v. 20, n. 1, p. 225-249, Mar. 2015. Disponível em: $<$ http://www.scielo.br/scielo.php?script=sci_arttext\&pid=S1414-40772015000100225\&ln $\mathrm{g}=\mathrm{en} \& \mathrm{nrm}=\mathrm{iso}>$. Acesso em: 05 Junho 2018.

GAALEN, A. V.; GIELESEN, R. Internationalization at Home: Dutch Higher Education Policies. Global and Local Internationalization, 149-154. Sense Publishers, 2016.

HODGSON, L. M. Coconstruções rizomáticas do conhecimento de inglês acadêmico em um curso de medicina. Dissertação de Mestrado em Letras. Universidade Estadual de Mato Grosso do Sul. Campo Grande, MS, 2019.

KNIGHT, J. Higher Education in Turmoil: The Changing World of Internationalization. Global perspectives on higher education volume 13. Sense publishers, Rotterdam, The Netherlands, 2008.

. Updating the definition of Internationalization. Center for International Higher

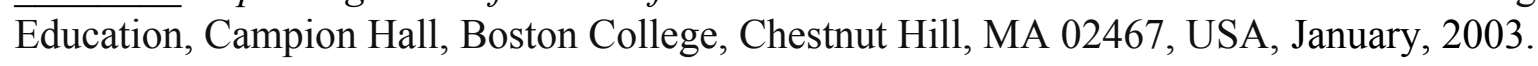
MARTINEZ, J. Z. Entre fios, pistas e rastros: os sentidos emaranhados da internacionalização da Educação Superior. Tese de doutorado - Faculdade de Filosofia, Letras e Ciências Humanas da Universidade de São Paulo: São Paulo, 2017. 
MENEZES DE SOUZA, L. M. Strategic Complicity in Neoliberal Educational Internationalization: the case of production of entrepreneurial subjects in Ciências sem Fronteiras. In: MACIEL, R. F; TILIO, R.; JESUS, D. M. de; BARROS, A. L. E. C.. (Org.) Linguística Aplicada para Além das Fronteiras. Campina: Pontes, 2018.

MACIEL, R. F.; BARBOSA, V. L. 'Mas professora, imagem não é texto!': as implicações dos multiletramentos nas aulas de língua portuguesa. Revista de letras norte@mentos, v. 11, p. 11, B.; MARTIN, I. MACIEL, R.F. Transnational epistemologies and practices in English language teacher education. In: AILA 8th World Congress of Applied Linguistics. Rio de Janeiro, 2017.

ROBSON, S. Internationalization at home: internationalizing the university experience of staff and students. Educação (Porto Alegre), v. 40, n. 3, p. 368-374, set.-dez. 2017

ROCHA, C. H.; MACIEL, R. F. Internacionalização do ensino superior como prática local: implicações para práticas educativas. Interletras, V.6, p.1-18, Edição número 24, de Outubro de 2016 a Abril de 2017.

ROCHA, C. H.; MACIEL, R. F. Internacionalização do ensino superior. In: Maciel, R. F; Tilio, R.; Jesus, D. M. de; Barros, A. L. E. C.. (Org.) Linguística Aplicada para Além das Fronteiras. Campina: Pontes, 2018.

OTA, G.H. Internacionalização da medicina como pratica local: aproximação e cooperação interinstitucional. Relatório de PIBEX. Universidade Estadual de Mato Grosso do Sul, Campo Grande-MS, 2018.

PAIVA, V. L. M. O. Affordances for language learning beyond the classroom. In BENSON,

Phil; REINDERS, Hayo. Beyond the language classroom. p. 59-71, 2011. Disponível em:

$<$ http://www.veramenezes.com/publicacoes.html> Acesso em 10/07/2019.

VERGARA, V.S.; MACIEL, R.F. Internacionalização da medicina como prática local: aspectos de tradução, mobilidade e visibilidade, ENEPEX, Campo Grande-MS, $2018 \mathrm{a}$.

VERGARA, V.S.; MACIEL, R. F. Internationalization at home: Medical students' discourses and performances in implementing English for Language proficiency. VI International Conference of multicultural discourse. Oral presentation. Tilburg University-The Netherlands, 2018b.

RUMBLEY, L. E.; ALTBACH, P. G. The Local and Global in Higher Education Internationalization: A Crucial Nexus. Global and Local Internationalization, 7-13. Sense Publishers, 2016.

Recebido em 18/03/2019. Aceito em 08/07/2019. 